\title{
Risk, Informational Asymmetry and Product Liability: An enquiry into conflicting objectives
}

\author{
Ram Singh \\ Email: ramsingh@econdse.org \\ Delhi School of Economics \\ University of Delhi
}

Working Paper No. 164

Centre for Development Economics

Department of Economics, Delhi School of Economics 


\title{
Risk, Informational Asymmetry and Product Liability:
}

An enquiry into conflicting objectives

\author{
Ram Singh \\ Department of Economics \\ Delhi School of Economics \\ University of Delhi \\ ramsingh@econdse.org \\ ramsingh_dse@yahoo.co.in
}

\begin{abstract}
Risky products cause two types of costs for society; the accident costs and the insurance costs. Liability rules allocate these costs between the parties involved. The expansion in the scope of product liability over the past thirty years has increased the cost of third-party liability insurance. However, the economic analysis of product liability rules has, generally, focused on only the accident costs. Some recent works have suggested that there is a strict trade-off involved when it comes to minimizing the accident costs and the insurance costs. In this paper, we have extended the economic analysis by considering both types of costs. An efficiency characterization of product liability rules has been provided by assuming that consumers lack in the knowledge about the risk. We have shown that even when consumers misperceive the product risk, it possible to achieve efficiency with respect to the insurance costs as well as the care levels.
\end{abstract}

Key words: Product liability, informational asymmetry, accident costs, insurance costs, Nash equilibrium, economic efficiency

Acknowledgement: I am grateful to Sabyasachi Das, Satish Jain and Anjan Mukherji for detailed comments. Also, I would like to thank the participants of the conference on Law, Economics and Development at JNU for valuable comments and suggestions. Errors are mine. 


\section{Introduction}

Product liability has acquired immense importance over the last 50 years. Most of the disputes involving product-caused injuries are governed by liability rules. ${ }^{1}$ Product liability is said to be one of the fastest growing cost components that manufacturers and retailers are facing these days. The manufacturing of risky products leads two associated costs for the society: the accident costs and the insurance costs. A substantial expansion in the scope of product liability over the past thirty years has increased the cost of the third-party liability insurance. ${ }^{2}$ Different product liability rules have different implications for the magnitude as also the allocation of the accident costs and the insurance costs. Therefore, legal rules regarding product liability have important implications for both the producers as well as the consumers of risky products.

The implications of product liability rules have been widely studied in the fairly extensive literature on the subject. Mckean (1970), Oi (1973), Goldberg (1974), Hamada (1976), Spence (1977), Polinsky (1980), Marino (1988), Shavell (1987), Spulberg (1989), Boyd (1994), Miceli (1997), and Endres and Lüdeke (1998) are some of the many works that have studied various aspects of product liability. However, the focus of these studies has been on the accident costs. Accident costs depend on the care levels opted by producer firms as well the consumers. In addition, production/consumption level of the good in question also affects the accident costs. Therefore, accident costs can be excessive either on account of suboptimal choice of care levels or due to an inefficient choice of production/consumption levels by the parties. Focusing on only the accident costs, the above mentioned studies have shown the following: When the product market is competitive and consumers are completely informed about the product risk, product liability rules are irrelevant for efficiency the market relationship between consumers and firms ensures an efficient outcome. However, when consumers have incomplete information about the product risk, the market mechanism cannot lead to an efficient outcome. In that case, product liability is required for economic efficiency. (See Spence (1977), Polinsky and Rogerson (1983), Schwartz and Wilde (1985), Shavell (1987, pp. 52-53), Doughety and Rein-

\footnotetext{
${ }^{1}$ Geistfeld (2000), Harvey and Parry (2000).

${ }^{2}$ Until 1970s liability insurance was a small cost of doing business. See Viscusi (2006).
} 
ganun (1997), Endres and Lüdeke (1998), and Sunding and Zilberman (1998)).

It is important to note that the need for product liability arises because of the informational asymmetry that marks the product related accidents. While the producer firms are supposed to be completely informed about the product risk, consumers, on the contrary, are unlikely to know it correctly. This is so because consumers cannot observe the care taken by the producer firm while producing the product. Moreover, even when consumers could be informed about the care taken by the firm, they may still be incompletely informed about the risk. Because they may not know the accident loss function (the value of the expected loss for the given care levels) correctly. The literature on product liability rules has concluded that when the care is unilateral and consumers misperceive the accident-risk, the rule of strict liability is efficient. The rule of negligence, on the contrary, is said to be inefficient. Under this rule, consumers consume too much [too little] of the product when they underestimate [over-estimate] the risk. Polinsky (1980), Shavell (1987, ch 3, pp. 67-68) and Geistfeld (2000) are some of the notable contributions that establish these claims. In other words, it has been argued that, as far as the accident costs are concerned, economic efficiency requires the producers to bear the entire accident costs.

However, the existing economic analyses of product liability rules suffer from a major shortcoming. They have focused on only the efficiency in terms of the accident costs, to a complete neglect of the insurance costs. As has been pointed out above, the substantial expansion in the scope of liability over the past thirty years has increased the cost of third party liability insurance for businesses. This is especially true for countries like the United States of America, England, Australia and some parts of Europe. $^{3}$ In view of this development, while studying product liability rules it is highly desirable to consider their implications in terms of the insurance costs along with the accident costs. For instance, in certain empirical or theocratical context, if it turns out that the firms are more efficient risk bearers, then the other things remaining the same a product liability rule will be efficient if it requires firms rather

\footnotetext{
${ }^{3}$ Though the problem of the increased claims and the insurance costs is not a new one, it has been a recurring issue in the US, England, Australia and elsewhere. In the US, for instance, liability premiums have increased from 1.13 billion USD in 1968 to 19.1 billion USD in 1988. See Viscusi (2006).
} 
than consumers to bear the residual accident loss.

However, Priest (1981, 87), Epstein (1985), Geistfeld (1992 2000), among others, have argued that it is the consumers rather than the firms that are likely to be more efficient bearer of the product risk. The main argument is that the insurance costs are likely to be lower for consumers as they can buy the 'first-party'4 insurance to cover the risk; firms, on the other hand, have to buy the costlier 'third party' insurance. ${ }^{5}$ These findings have striking implications for the existing claims about the economic efficiency (or the lack of it) of various product liability rules. More pointedly, these findings imply that, ceteris paribus, a liability rule is efficient if it requires consumers rather than firms to bear the residual accident loss.

Therefore, if we expand the scope of economic analysis to incorporate insurance costs, there appears to be a trade-off between the efficiency in terms of accident costs, on one hand, and the efficient risk-bearing on the other hand. The efficiency on the first count requires firms to bear the risk, while that on the second count may have consumers as the residual risk-bearers. This trade-off becomes all the more strict if we consider accident contexts that involve the bilateral care. To see why, note that when insurance costs are lower for consumers, other things remaining the same, they should bear the accident costs. However, in the context of bilateral-care accidents, it is well known that when consumers are the residual bearers of accident loss, as under the rule of negligence, the outcome cannot be efficient. Some works have argued that the outcome is inefficient both in terms of care levels as well as the consumption/production levels (for discussion see Shavell, 1987 ch. 3, also see Geistfeld, 2000). Therefore, an implication of the existing claims regarding the accident costs and the insurance costs is that a liability rule can achieve efficiency with respect to insurance costs only by sacrificing efficiency with respect to accident costs, and vice-versa. This paper, in contrast, shows that suitably designed liability rules can resolve this trade-off to a significant extent.

\footnotetext{
${ }^{4} \mathrm{~A}$ first party insurance covers the risk faced by the insuree himself. Third party insurance, in contrast, is purchased to cover the risk that the insuree ( say a producer) may create for a third party ( say a consumer).

${ }^{5}$ For arguments and more references see Priest (1981, 87), Epstein (1985), Geistfeld (2000).
} 
When we extend the framework of economic analysis of product liability rules to include insurance costs, in principle, there can be several methodological approaches. In this paper, we start the efficiency analysis by focusing first only on the efficiency with respect to accident costs. To this end, we provide a characterization of efficient product liability rules, by considering the two components of the accident costs - the care levels and the production/consumption levels. Such efficiency characterization is meaningful in its own right. Since, it enables us to delineate those features of product liability rules that are crucial for efficiency (or the lack of it) in terms of accident costs. More importantly, this exercise enables us to extend the efficiency analysis of product liability rules to consider accident costs and insurance costs simultaneously. This approach has turned out to be very helpful in the search of the possibility of consistency or otherwise among various seemingly conflicting requirements of economic efficiency. We explore the issue by making alternative assumptions about insurance costs. In particular, we show that even when there are informational asymmetries regarding the product risk, a suitably designed product liability rule can ensure the efficient care as well as the efficient risk bearing.

There is another body of literature for which our results are relevant. In some interesting works, the need for the tort liability of firms has been questioned. In these contributions, it has been argued that the informational asymmetry in which consumers lack the information about product risk might not be a problem that necessarily requires that firms be made liable for accident losses. Since, firms might signal the information regarding product related risk to consumers through price and warrantees etc. (for references see Bagwell and Riordan, 1991). In response to these contributions, many studies have argued that because of inadequate incentives (for informing consumers about the risk) on the part of firms and limited capability of consumers to process the information available, unregulated market cannot result in optimum care by firms and optimum consumption by consumers. Also, in some contexts consumers may not prefer better information about the quality of the product (Schlee, 1996). ${ }^{6}$ Leaving aside the issues of signaling mechanisms and the relative

\footnotetext{
${ }^{6}$ For arguments and discussion, besides afore-mentioned studies see Beales, Craswell and Salop (1981), Priest (1991), Grossman (1981), Landes and Posner (1987, ch. 10), Viscusi (1991), Burrows (1992), Schwartz (1995), Caves and Green (1996), Hamilton (1998), Arlen (2000), and Geistfeld (2000), etc.
} 
merits of tort liability vis-a-vis other corrective mechanisms, we show that as long as other mechanisms are imperfect in signaling the risk, there can be an efficiencyenhancing role for tort liability. Moreover, we show that even when firms have no liability in equilibrium, a suitable designed product liability rule can convey the information to consumers that is crucial for efficiency.

Finally, in view of our framework and results, we study the product liability rules that are prevailing in India.

The analysis is carried out in a partial-equilibrium framework. The framework of analysis, though very similar to the standard framework, is different on at least the following two counts. First, it is unified and more general than the standard framework. No assumptions are imposed on the costs of care and expected loss functions, apart from assuming the existence of a pair of care levels which minimizes the direct costs of accident. Second, it provides a formal analysis of the entire class of product liability rules in the context of bilateral care accidents where there is afore-mentioned informational asymmetry. Here it should be noted that the existing formal analyses have largely been undertaken only for the rule of negligence and the rule of strict liability. In Shavell $(1980,89)$ the efficiency of the rule of strict liability with the defense of the contributory negligence has been claimed without providing a formal proof. As a corollary of our results, we formally show that the claim in Shavell (1980, 87) holds in a broader framework.

Section 2 introduces the framework of analysis that outlines the notations and the assumptions made in the paper. Section 3 focuses on only the accident costs and provides an efficiency characterization of efficient product liability rules. In Section 4 we extend our analysis to consider the insurance costs. Section 5 undertakes economic analysis of product liability rules in India. We conclude in Section 6 with remarks on the nature of results in the paper.

\section{The Social Optimization Problem}

2.1 Notations and Assumptions: We consider accidents that involve two parties, a consumer and the producer firm. Product-related accidents differ from the ac- 
cidents generally considered under liability rules in that, in product-related accidents injurers (firms) and victims (consumers) engage in a market exchange. Moreover, this exchange is, supposedly, with the knowledge that the product might cause injuries to the consumer later on. However, both the producer firm as well as the consumer can take care to reduce the expected accident loss. The output of the firm and the amount of purchase made by the consumer are treated as their respective activity levels. It is assumed that in the event of an accident the entire loss falls on the consumer. We denote by:

$x$ the cost of care taken by the consumer, $x \geq 0$,

$y$ the cost of care taken by the firm, $y \geq 0$,

$X=\{x \mid x$ is the cost of some feasible level of care for the consumer $\}$,

$Y=\{y \mid y$ is the cost of some feasible level of care for the firm $\}$,

$\pi$ the probability of occurrence of an accident,

$H$ the loss in case an accident actually materializes, $H \geq 0$,

$L$ the expected loss due to the accident. $L$ is thus equal to $\pi H$,

$L_{c}$ the expected accident loss as perceived by the consumer, ${ }^{7}$

$n$ number of firms in the industry,

$q$ number of units of the product produced by a firm,

$u_{i}($.$) marginal consumption benefit to the i^{\prime}$ th consumer from the product,

$p$ the market price of one unit of the product,

$P($.) the inverse demand function for the industry,

$C($.) the cost of production function for a firm,

$D A C$ the direct accident costs - the sum of costs of care and the expected accident loss, i.e., $D A C=x+y+L(x, y)$.

Analysis is undertaken in a simple competitive partial-equilibrium framework. We assume:

(A1): Costs of care to be strictly increasing functions of care levels. As a result, the cost of care for a party also represents the level of care for that party. Therefore, $X$ is the care choice set for the consumer, and $Y$ is the care choice set for the firm. Also, $0 \in X$ and $0 \in Y$.

(A2): $\pi$ and $H$ are functions of $x$ and $y ; \pi=\pi(x, y), H=H(x, y)$.

\footnotetext{
${ }^{7} L_{c}$ is the product of the probability of accident and the accident loss in the event of accident as are perceived by the consumer. See Assumption (A9).
} 
(A3): $L$ is thus a function of $x$ and $y ; L=L(x, y)$. Clearly, $L \geq 0$.

(A4): $L$ is a non-increasing function of care level of each party. That is, a larger care by either party, given the care level of the other party, results in lesser or equal expected accident loss. Decrease in $L$ can take place due to decrease in $\pi$ or $H$ or both.

(A5): $X, Y$, and $L$ are such that DAC minimizing pair of care levels is unique and it is denoted by $\left(x^{*}, y^{*}\right)$, where $x^{*}>0$, and $y^{*}>0$. That is, the term $x+y+L(x, y)$ is uniquely minimized at $\left(x^{*}, y^{*}\right)$. As a result, for all $(x, y) \neq\left(x^{*}, y^{*}\right)$, we have $x+y+L(x, y)>x^{*}+y^{*}+L\left(x^{*}, y^{*}\right)$.

(A6): Both firms and consumers are rational and risk-neutral. Moreover, the rationality of each party is a common knowledge. The assumption regarding the riskneutrality of the party is relaxed in Section 4, wherein we consider insurance costs.

(A7): The legal due care standard (level) for the firm, wherever applicable (say under the rule of negligence), is set at $y^{*}$. Similarly, the legal standard of care for the consumer, wherever applicable (say under the rule of strict liability with defense), is $x^{*}$. Also, $y \geq y^{*}$ means that the firm is taking at least the due care. In that case it will be called nonnegligent. $y<y^{*}$ would mean that it is taking less than the due care, i.e., it is negligent. Likewise, for the consumer.

(A8): Marginal utility of the product is diminishing, i.e., $u_{i}^{\prime}()<$.0 .

(A9): Neither party observes the care taken by the other party. Firms are completely informed about the expected loss function $L(x, y)$. Consumers, on the other hand, are not completely informed about the expected loss; when the expected loss is $L(x, y)$, a consumer perceives it to be $L_{c}(x, y)$, where $L_{c}($.$) may not be equal to L($.$) . However,$ $L_{c}(x, y) \geq 0$ and satisfies $(\mathrm{A} 4)$.

Note that (A1)-(A9) are standard assumptions in the economic analysis of liability rules. Moreover, it should be noted that $x, y, \pi, H$, and $L$ are defined per unit of the product.

2.2 Social Objective: For the ease of exposition, the product is assumed to be homogeneous in all respects except the expected accident loss associated with the product use. The product market is assumed to be competitive; ${ }^{8}$ there are $n$ identical

\footnotetext{
${ }^{8}$ As is the case with our model, it is shown in Epple and Raviv (1978) and Geistfeld (2000) that as long as DAC per unit of product are independent of the output level, the results obtained in a
} 
firms each producing an output of $q$ units. As was noted above, the direct accident costs per unit of product (DAC) are the sum of costs of care by the two parties and the expected loss due to accident; $\mathrm{DAC}=x+y+L(x, y)$. Therefore, the direct accident costs per firm are $q[x+y+L(x, y)]$, and the direct accident costs for the entire industry are $n q[x+y+L(x, y)]$. $u_{i}($.$) denotes consumer i^{\prime}$ s marginal consumption benefit from the product, and $u_{i}^{\prime}()<$.0 . $P($.$) is the inverse demand function for$ the industry. It is assumed that the cost of production function, $C(q)$, is such that there is a unique positive output level at which a firm's average costs of production, $C(q) / q$, are minimized. This assumption is not necessary for our results to hold. ${ }^{9}$ In this setup, the social surplus is equal to the total benefits from $n q$ units of the product that consumers derive (approximated by the area under the industry's inverse demand curve) minus total costs of production (the sum of costs of production and the accident costs). The social objective is to choose $x, y, q$ and $n$ so as to maximize the social surplus

$$
\int_{0}^{n q} P(z) d z-n C(q)-n q[x+y+L(x, y)] .
$$

The first order conditions for $q$ and $n$ are given by (2) and (3), respectively.

$$
\begin{aligned}
& P(n q)=C^{\prime}(q)+x+y+L(x, y) \\
& P(n q)=\frac{C(q)}{q}+x+y+L(x, y) .
\end{aligned}
$$

Let $\bar{q}(x, y)$ and $\bar{n}(x, y)$ uniquely solve (2) and (3) simultaneously. In other words, given $x$ and $y$ as levels of care taken by the consumer and the firm, when $n=\bar{n}$, at $\bar{q}$ marginal consumption benefit is equal to marginal total cost of the product - marginal cost of production plus DAC. That is, $\bar{q}$ is the optimal production level for the firm. Similarly, when $q=\bar{q}$, at $\bar{n}$ marginal consumption benefit is equal to average total cost of the product, i.e., $\bar{n}$ is the optimal number of the firm in the industry. Note that $\bar{q}$ and $\bar{n}$ are functions of $x$ and $y$.

competitive setting will hold more or less even when the market is not competitive. For the effects of market-power on the output and the choice of care by firms and the related issues see Beals, Craswell and Salop (1981), Schwartz and Wild (1982), Polinsky and Rogerson (1983), Marino (1988 a, b), Spulber (1989, pp.408-410), Faulhaber and Boyd (1989), and Boyd (1994).

${ }^{9}$ However, if we take $C(q)=c q$, where $c>0$, then equilibrium number of firms will be indeterminate. 
Remark 1: Since accident costs are linear in output, the socially optimum levels of $x$ and $y$ are independent of the quantity of the product produced/consumed (see eq. (1)-(3)). In other words, economic efficiency requires that the parties' care levels minimize DAC, regardless of the consumption level of the consumer and the production level of the firm. Furthermore, (2) and (3) imply that $C^{\prime}(q)=C(q) / q$. That is, $\bar{q}$ is the efficient level of output for the form, irrespective of the choice of $x$ and $y$.

Let $\bar{q}\left(x^{*}, y^{*}\right)=q^{*}$ and $\bar{n}\left(x^{*}, y^{*}\right)=n^{*}$. That is, when both the parties take efficient - DAC minimizing - care, $q^{*}$ and $n^{*}$, respectively, denote the optimal level of production for a firm and the number of firms in the industry.

2.3 Product Liability Rules: A Product Liability Rule (PLR) uniquely determines the proportions in which the consumer and the firm share the loss $H$, in the event of an accident, as a function of the proportions of their (non)negligence. Let $I$ denote the closed unit interval $[0,1]$. Consider any $X, Y, L$, and $\left(x^{*}, y^{*}\right)$. To capture parties' (non)negligence we define functions $g: X \mapsto I$ and $h: Y \mapsto I$ so that:

$$
\begin{gathered}
g(x)=x / x^{*} \text { if } x<x^{*}, \text { and } g(x)=1 \text { otherwise; and } \\
h(y)=y / y^{*} \text { if } y<y^{*}, \text { and } h(y)=1 \text { otherwise. }
\end{gathered}
$$

In view of Assumption (A7), the legal standard for the firm, wherever applicable, is set at $y^{*}$. Therefore, $h(y)=1$ would mean that $y \geq y^{*}$, i.e., the firm is taking at least the due care and it would be called nonnegligent. $h(y)<1$ would mean that $y<y^{*}$, i.e., the firm is negligent. $h(y)$ and $1-h(y)$ will be its proportions of nonnegligence and negligence, respectively. Similarly, for the consumer.

Formally, a PLR can be defined as a function

$$
f:[0,1]^{2} \mapsto[0,1]^{2}, \text { such that: } f(g(x), h(y))=(s, t),{ }^{10}
$$

where $s \geq 0[t \geq 0$ ] is the proportion of loss that the consumer [ the firm] is required to bear. $s+t=1$. From the definition of the function $f$ it is clear that in principle there can be infinitely many PLRs.

2.4 Competitive Equilibrium: If an accident with a loss of $H$ materializes, the court will require the firm to bear $t(x, y) H$, in the form of liability payment

\footnotetext{
${ }^{10}$ This definition of a liability rule is quite general see Jain and Singh (2002), and Singh (2003).
} 
to be made to the consumer. $t$ is determined by the PLR in force and is a function of $x$ and $y$. The expected accident costs of a party are the sum of the cost of care taken by it plus its expected liability. A firm's expected accident costs, therefore, are: $y+t(x, y) \pi(x, y) H(x, y)$, i.e., $y+t(x, y) L(x, y)$. As far as the consumer is concerned, since he perceives the expected loss to be equal to $L_{c}(x, y)$, he will perceive the expected liability payment (made by the firm) to be equal to $t(x, y) L_{c}(x, y)$. Therefore, from a consumer's perspective his expected accident costs are: $x+L_{c}(x, y)-t(x, y) L_{c}(x, y)$, i.e., $x+s(x, y) L_{c}(x, y)$, as $1-t=s$.

The assumption of competitive market implies that $p$, the per unit market price of the product, is given for both the parties and is equal to the total marginal cost of production - marginal cost of production plus marginal expected liability of the firm. When consumers misperceive the risk, demand for the product is a function of the perceived full price. Given the relevant PLR and the level of care taken by the firm, 'perceived' full price per unit of product is equal to the market price plus the expected accident costs that the consumer expects to bear under the rule, i.e, $p+x+s(x, y) L_{c}(x, y)$. Therefore, a consumer $i$ 's problem is to choose the quantity $q_{i}$ and the level of care $x$ to maximize his utility

$$
\int_{0}^{q_{i}} u_{i}(z) d z-p q_{i}-q_{i}\left[x+s(x, y) L_{c}(x, y)\right]
$$

resulting in the first order condition as

$$
u_{i}\left(q_{i}\right)=p+x+s(x, y) L_{c}(x, y)
$$

This means that given consumers' misperception about $L$, consumers' problem is equivalent to that of choosing the quantity $Q$ and the care $x$ to maximize

$$
\int_{0}^{Q} P(z) d z-p Q-Q\left[x+s(x, y) L_{c}(x, y)\right]
$$

The first order condition for $Q$ is

$$
P(Q)=p+x+s(x, y) L_{c}(x, y)
$$

Note that when consumers choose their demand for the product rationally, each consumer's marginal benefit, $u_{i}(z)$, is equal to $P(Q)$. Therefore, $(5)$ is maximized w.r.t. $Q$ if ceteris-paribus each consumer chooses his demand for the product rationally. In other words, other things remaining the same, rational choice by individual consumers 
would lead to the maximization of consumers' surplus. In our analysis, however, this maximization is constrained by the informational asymmetry.

Similarly, given the PLR and the care taken by the consumer, a firm's problem is to choose the quantity $q$ and the level of care $y$ so as to maximize its profits

$$
p q-C(q)-q[y+t(x, y) L(x, y)]
$$

The first order condition for $q$ is

$$
p=C^{\prime}(q)+y+t(x, y) L(x, y) .
$$

Free entry assumption implies that profit of each firm is zero, i.e.,

$$
p q=C(q)+q[y+t(x, y) L(x, y)]
$$

From $(4) \&(5)$ it is clear that the optimum level of care for the consumer is independent of his levels of consumption. In other words, a rational and risk-neutral consumer chooses $x$ that minimizes his expected accident costs, $x+s(x, y) L_{c}(x, y)$, regardless of his level of consumption. Analogous argument in view of (7)\&(8) implies that given $x$, the firm chooses $y$ that minimizes its expected accident costs, $y+t(x, y) L(x, y)$.

An equilibrium is defined as a tuple $<\hat{Q}, \hat{p}, \hat{q}, \hat{n}, \hat{x}, \hat{y}>$ such that: $\hat{Q}=\hat{n} \hat{q}$; and $\hat{Q}$, $\hat{p}$, and $\hat{q}$ satisfy (6), (8) and (9), respectively; and, $\hat{x}=\arg \min _{x \in X}\left\{x+s(x, y) L_{c}(x, y)\right\}$ and $\hat{y}=\arg \min _{y \in Y}\{y+t(x, y) L(x, y)\}$.

Now, from (6)\&(8) in equilibrium we have

$$
P(Q)=P(n q)=C^{\prime}(q)+x+y+s(x, y) L_{c}(x, y)+t(x, y) L(x, y)
$$

and from (6) and (9) we get

$$
P(Q)=P(n q)=\frac{C(q)}{q}+x+y+s(x, y) L_{c}(x, y)+t(x, y) L(x, y)
$$




\section{Efficiency with respect to the accident costs}

In this section, we restrict the analysis only to the accident costs. In other words, we study the incentives that various product liability rules create for the parties for the choice of the care levels and the production/consumption levels.

When consumers misperceive the risk, the actual output level per firm and the number of firms in the industry are given by (10) and (11). However, for the given levels of care opted by the consumers and the firms, the socially optimum level of production per firm and the number of firms in the industry are given by (2) and (3), respectively. Generally the solution to $(10) \&(11)$ will be different from that of $(2) \&(3)$. (10)\&(11), however, imply that $C^{\prime}(q)=C(q) / q$, i.e., in equilibrium output per firm is efficient (Remark 1). But, from (10) and (11) it follows that even if we assume that both the parties have opted for efficient care levels, when consumers misperceive the risk, i.e., when $L_{c} \neq L$ the number of firms in the industry is not necessarily efficient. Therefore, even if we exclude the insurance costs and restrict our attention only to the accident costs, a PLR may cause inefficiency on the following two counts: (a) it may induce the parties to take inefficient care, and $(b)$ it may induce inefficient (total) production and hence consumption. In view of the above discussion, it should be noted that the second kind of inefficiency can occur even when that of the first type is not there.

Remark 2: Let $L_{c} \neq L$. If under a PLR $s=0$ or $t=1$ in equilibrium, (10)\&(11) will exactly be the same as $(2) \&(3)$. Therefore, both the quantity produced by the firms as well as the number of firms in the industry will be efficient. This, however, will not be the case when $s \neq 0$.

As regards to care levels, a rule is said to be efficient iff in equilibrium it induces efficient care by both the parties. To be efficient on both the counts, the rule should also induce efficient output for the industry.

\section{Definition 1: Efficient Product Liability Rule}

A PLR, $f$, is said to be efficient with respect to the accident costs iff, in equilibrium it simultaneously induces the choice of the efficient care levels by both the parties, the efficient output per firm and the efficient number of firms in the industry. 
Formally, $f$ is efficient for given $X, Y, L,\left(x^{*}, y^{*}\right)$, and $C(q)$, iff: $\left(x^{*}, y^{*}\right)$ is a unique Nash equilibrium ( N.E.); ${ }^{11}$ and in equilibrium $q^{*}$ and $n^{*}$ solve (10) and (11), simultaneously. A PLR, $f$, is defined to be efficient iff it is efficient for every possible choice of $X, Y, L,\left(x^{*}, y^{*}\right)$, and $C(q)$.

In the following, we provide a characterization of efficient PLRs when there is informational asymmetry vis-a-via the expected loss function, i.e., when $L_{c} \neq L$. That is, we derive a necessary and sufficient condition for efficiency of a PLR. Formally, we show that when $L_{c} \neq L$, a PLR $f$ is efficient iff $f$ satisfies the condition of 'negligent consumer's liability' (NCL).

Definition 2: Condition of Negligent Consumer's Liability (NCL):

A PLR, $f$, is said to satisfy the condition NCL iff its structure is such that (i) whenever the consumer is nonnegligent, i.e., whenever he has taken at least the due care, the entire loss in the event of accident is borne by the firm, irrespective of the level of care taken by the firm, and (ii) when the consumer is negligent and the firm is not, the entire loss in the event of accident is borne by the consumer. Formally, a PLR $f$ satisfies condition NCL iff:

$$
(\forall h \in[0,1])[f(1, h)=(0,1)] \text { and }(\forall g \in[0,1))[f(g, 1)=(1,0)] \text {. }
$$

Remark 3: A PLR may specify the due care standards for both the consumer and the firm, or for only the consumer, or for only the firm, or for neither of the parties. It should be noted that a PLR can satisfy the condition NCL only if it specifies the due care standards for the consumer; it may or may not set the due care standard for the firm. When a PLR does not specify the due care standard for the consumer, it cannot satisfy the condition NCL.

Theorem 1 A PLR is efficient for every possible choice of $X, Y, L,\left(x^{*}, y^{*}\right), L_{c}$, and $C(q)$ only if it satisfies the condition NCL.

The theorem shows that the NCL is a necessary condition for a PLR to be efficient in terms of the care levels as well as the output levels. For a formal proof see the Appendix. Note that under the condition NCL, a solely negligent party is liable for

\footnotetext{
${ }^{11}$ Throughout the paper whenever we refer to N.E., the strategy of a party will refer to the level of care taken by this party. We consider only the pure strategy Nash equilibria.
} 
the entire accident loss. However, when both the parties are nonnegligent, it the firm that is liable for the entire accident loss. Therefore a PLR can violate the condition NCL by (a) making a solely negligent party bear only a fraction of the accident loss and/or (b) by making the consumer liable for a fraction of the accident loss when both the parties are nonnegligent. The proof of Theorem 1 shows that when (a) hold then a negligent party will not fully internalize the consequences of its action, as a result at least one party will take less than the efficient care. On the other hand, when (b) hold then the consumer will bear at least a fraction of the accident loss even when he opts for the efficient care level. This, in view of Remark 2, implies that even if both parties take efficient care, the production levels and consumptions levels will be inefficient.

As argued before, in order to satisfy the condition NCL, a PLR has to specify the due care standards for (i) both the consumer as well as the firm, or (ii) for only the consumer. Suppose a PLR belongs to subclass (i). In that case, the due levels of care are part of the common knowledge. Recall that the due levels of care are assumed to be set at levels that are appropriate for efficiency, i.e., at $x^{*}$ and $y^{*}$. Therefore, under a PLR belonging to subclass (i), consumers - because of this common knowledge get to know of DAC minimizing pair, $\left(x^{*}, y^{*}\right)$, from the legal rule itself. ${ }^{12}$ That is, under PLRs in subclass (i), the expected loss function as perceived by a rational consumer, $L_{c}$, may not be identical with $L$ but will be such that $\left(x^{*}, y^{*}\right)$ uniquely solves $\min \left\{x+y+L_{c}(x, y)\right\}$. Formally, in the case of PLRs that specify the due care standards for both the parties, $L_{c}$ is such that it satisfies the following property:

$$
\begin{aligned}
& \operatorname{Property}(\mathbf{P} 1):(\forall(x, y) \in X \times Y)\left[x^{*}+y^{*}+L_{c}\left(x^{*}, y^{*}\right) \leq x+y+L_{c}(x, y), \&\right. \\
& \left.(x, y) \neq\left(x^{*}, y^{*}\right) \Rightarrow x^{*}+y^{*}+L_{c}\left(x^{*}, y^{*}\right)<x+y+L_{c}(x, y)\right]
\end{aligned}
$$

Of course, when $L_{c}=L, L_{c}$ satisfies (P1). Therefore, depending on the PLR in question and consumers' risk perception, $L_{c}$ may or may not satisfy $(\mathrm{P} 1)$. The next theorem shows that the NCL is a sufficient condition for the efficiency of any PLR, even when consumers misperceive the risk, i.e., even when $L_{c} \neq L$.

\footnotetext{
${ }^{12}$ As a matter-of-fact some rules, such as the rules of negligence with the defense, comparative negligence, strict liability with the dual defense, specify the due care standard for both the parties.
} 
Theorem 2 A PLR is efficient for every possible $X, Y, L,\left(x^{*}, y^{*}\right), L_{c}$, and $C(q)$, iff it satisfies the condition NCL.

Theorem 2 establishes that as far as the accident costs are concerned, PLRs that satisfy the condition NCL are efficient for every possible application, irrespective of consumers' misperception about the product risk. To put the argument informally, it is shown that if a PLR satisfies the condition NCL then under it $\left(x^{*}, y^{*}\right)$ is a unique N.E. That is, the consumer and the firm will opt for the DAC minimizing care levels, i.e., $x^{*}$ and $y^{*}$, respectively. Now, a choice of $x^{*}$ by the consumer implies that $s=0[t=1]$. In other words, in equilibrium the consumer will always opt for $x^{*}$, and consequently will not bear any risk, making the risk-misperception irrelevant. Also, when $[t=1]$ market price will fully reflect the product-risk (see (8)). On the contrary, from Theorem 1, PLRs that violate the condition NCL cannot be efficient in all applications. One violation of the condition NCL implies that when $x^{*}$ is opted by the consumer and $y^{*}$ is opted by the firm, $s>0$ or $t<1$, i.e., less than full liability of the firm and at least some risk-bearing by consumers. From (10)\&(11) and the proof of Theorem 1, this results in inefficiency. Therefore, as long as the market mechanisms are imperfect in signalling the product-risk, i.e, as long as $L_{c} \neq L$, there will be inefficiency in the absence of the residual liability of the firms, and product liability rules can play an efficiency enhancing role.

The rule of the strict liability with the defense of contributory negligence holds the consumer liable iff he was negligent. Therefore the rule can be defined as: $(g=$ $1 \rightarrow s=0)$ and $(g<1 \rightarrow s=1)$. Clearly, the rule satisfies the condition NCL and therefore is efficient. Therefore, as an implication, Theorem 2 provides a formal proof to the claim about the efficiency of the rule of strict liability with the defense of contributory negligence by Shavell $(1980,87)$ in a broader context. Based upon the fulfillment or otherwise of the condition NCL, we immediately get the following corollary 1 from Theorem 2 .

Corollary 1 The rule of strict liability with the defense of contributory negligence as well as the rule of strict liability with the defense of dual contributory negligence, ${ }^{13}$ are efficient (in terms of care levels, output per firm and the number of firms in the

\footnotetext{
${ }^{13}$ the rule of strict liability with the defense of dual contributory negligence can be defined as: $(g=1 \rightarrow s=0)$ and $(g<1 \& h<1 \rightarrow s=0)$ and $(g<1 \& h=1 \rightarrow s=1)$.
} 
industry) for every $X, Y, L,\left(x^{*}, y^{*}\right), L_{c}$ and every $C(q)$. On the other hand, the rules of no liability, strict liability, negligence, negligence with the defense of contributory negligence, and comparative negligence are not efficient.

Remark 4: Both the rule of strict liability with the defense of contributory negligence as well as the rule of strict liability with the defense of dual contributory negligence satisfy the condition NCL. However, it should be noted that the condition is less restrictive than either of these rules. In particular, the condition does not impose any restriction on liability assignment when both the parties are negligent. Therefore, in principle it is possible to design more rules that satisfy the condition and therefore are efficient.

So far we have been focusing on the efficiency both in terms of care levels as also the output/consumption levels. Next, we show that if we exclusively focus on the the efficiency in terms of care levels, it is possible to derive a weaker condition for efficiency of a PLR. As noted earlier, several rules set the due standards of care for both the parties. If a PLR sets the due care standards for both the parties then for any arbitrary $L_{c}$ the following claim holds.

Theorem 3 A PLR, $f$, is DAC minimizing for every $X, Y, L,\left(x^{*}, y^{*}\right)$, and $L_{c}$, if it sets the due care standards for both the parties, and is such that $[g<1 \rightarrow[f(g, 1)=(1,0)], \& h<1 \rightarrow[f(1, h)=(0,1)]], \&[f(1,1)=(1,0)$ or $(0,1)]$. Suppose a PLR is such that 1) it sets the due care standards for both the parties, 2) it holds only one party (any of the two) to be fully liable when both the parties are nonnegligent, and 3) when one party is negligent and the other is not then the solely negligent party bears all the losses. Theorem 3 says that irrespective of consumers' misperceptions of the product risk, such a PLR is efficient as far as direct accident costs are concerned. For proof see the Appendix. Note that under a PLR, as in the statement of Theorem $3, L_{c}$ will satisfy the Property $(\mathrm{P} 1)$. When $f(1,1)=(0,1)$ hold, i.e., when the firm is the residual loss bearer, the rule satisfies the condition NCL and therefore is DAC minimizing. When $f(1,1)=(1,0)$, i.e., even when the consumer is the residual loss bearer, the proof shows that both the parties will take efficient care under the rule. 
It is pertinent to compare the claim of Theorem 3 with the existing claims in the literature. In the context of bilateral-care accidents, it has been argued that under a product liability rule if consumers are the residual bearers of accident loss, then the rule will be inefficient both in terms of the care level opted by the parties as well as the output of the industry. (see Shavell, $1987 \mathrm{ch}$. 3, also Geistfeld, 2000). Theorem 3 , in contrast, shows that even when consumers misperceive the product risk and are the residual bearers of accident loss, a suitably designed PLR can ensure efficient care by providing the information that is crucial for economic efficiency.

It should be noted that each of the standard liability rules that set the due care levels for both the parties satisfies the condition in the statement of Theorem 3. As an implication of Theorem 3, we get the following corollary.

Corollary 2 The rule of strict liability with the defense of dual contributory negligence, the rule of negligence with the defense of contributory negligence, and the rule of comparative negligence induce the efficient care levels from both the parties even in the presence of informational asymmetry regarding the product risk.

\section{Efficiency with respect to the accident costs as well as the insurance costs}

In this section, we extend the analysis to include the insurance costs. The analysis has been undertaken by making alternative assumptions about the insurance costs, namely when the insurance costs are lower for the firms and when these costs are lower for the consumers. Since there are many aspects of insurance that imping on the total insurance costs, whether the insurance costs are lower for the firms or for the consumers is a matter of empirical analysis.

\subsection{When the insurance costs are lower for the firms}

For various reasons, the insurance costs can be less for the firms than those for the consumers. It could simply be that the firms are risk-neutral, whereas the consumer are risk-averse. In some instances even when both firms and consumers are riskaverse, the administrative costs of insurance policies could be significantly lower for firms since a single policy bought by them can cover many accidents resulting from 
their products. The consumers on the other hand, will have to buy individual policies and this, as some argue, results in large administrative costs.

When the insurance costs are lower for the firms, ceteris paribus, a PLR will be efficient if and only if under it firms rather than consumers bear the entire expected accident loss. We already know from Theorem 2 that when both parties are riskneutral, a PLR is efficient with respect to the accident costs, i.e., with respect to the care levels and the productions/consumption levels, if and only if it satisfies the condition NCL. Now suppose that the firms are risk-neutral and consumers are riskaverse. Since, under condition NCL a consumer can avoid the risk altogether simply by spending $x^{*}$ on care. Therefore, even a risk-averse consumer will not take excessive care. A risk-averse consumer, however, has stronger incentive to take care equal to $x^{*}$ in order to avoid the risk of bearing accident loss. This implies that under condition NCL, the entire residual expected accident loss is borne by the party with the least insurance costs, i.e., the firm. Also, it is immediate to see that under condition NCL the optimal choice for the firm is $y^{*}$ and

$$
p=C^{\prime}(q)+y^{*}+L\left(x^{*}, y^{*}\right), \text { i.e. },
$$

the market price perfectly captures the expected accident loss leading to an optimal level of consumption. Therefore, if the insurance costs are lower for the firms as they are risk-neutral and consumers are risk-averse, a PLR is efficient with respect to care levels, the productions/consumption levels and the insurance costs, if and only if it satisfies the condition NCL.

The same argument will hold when firms are risk-averse but can buy insurance at a lower cost, provided that the policy designed by the insurer can avoid the problem of moral hazards. We assume that the insurer is able to do so. ${ }^{14}$ Therefore, if the insurance costs are less for firms than for consumers, a PLR is efficient with respect to the accident costs as well as the insurance costs, if and only if satisfies the condition NCL. Formally,

Theorem 4 When the insurance costs are lower for the firms, for every possible choice of $X, Y, L,\left(x^{*}, y^{*}\right), L_{c}$ and $C(q)$, a PLR is efficient with respect to the accident costs as well as the insurance costs, if and only if it satisfies the condition NCL.

\footnotetext{
${ }^{14}$ Needless to say that this is a very strong assumption. See concluding remarks on this.
} 
The following corollary immediately follows from Theorem 4.

Corollary 3 When the insurance costs are lower for the firms, the rules of strict liability with the defense of contributory negligence, and the rule strict liability with the defense of dual contributory negligence, are efficient in terms of care levels, output/consumption levels as well as the insurance costs. On the other hand, the rule of no liability, the rule of strict liability, the rule of negligence, the rule of negligence with defense of contributory negligence, and the rule of comparative negligence are not.

\subsection{When insurance costs are lower for the consumers}

As is argued in the introduction, Priest (1981, 87), Epstein (1985), Geistfeld (1992 2000), among others, have argued that consumers rather than firms could be the efficient bearer of the product risk. The main argument is that the risk-averse consumers will buy the 'first-party' insurance to cover product risk. Moreover, insurance against the product risk can be a part of the general coverage purchased by consumers. Firms, on the other hand, have to buy the costlier 'third party' insurance. Therefore, insurance costs can be less for consumers than those for firms. In theory it could also be the case when consumers are risk-neutral and firms are not.

When the insurance costs are less for the consumers, ceteris paribus, a PLR is efficient if and only if under it consumers bear the entire expected accident loss. As an implication of Theorem 1, on the contrary, we know that that a PLR can be efficient with respect to the care levels as well as the productions/consumption levels, only if it requires firms to bear the entire residual expected accident loss. Therefore, when insurance costs are lower for the consumers, no PLR can be efficient with respect to care levels, the productions/consumption levels as well as insurance costs, simultaneously.

The above analysis implies that when the consumers are efficient risk-bearers, no liability rule can be efficient with respect to the accident costs and the insurance costs. Note that this claim is true even if the availability of insurance does not cause any moral hazards. However, there are PLRs that are efficient with respect to care levels as well as the insurance costs simultaneously, even when the insurance costs are less for the consumers. Formally we have the following result: 
Theorem 5 When insurance costs are lower for consumers, for every possible choice of $X, Y, L,\left(x^{*}, y^{*}\right), L_{c}$, and $C(q)$, a PLR, $f$, is efficient with respect to the care levels as well as the insurance costs, if it sets the due care levels for both the parties and is such that,

$$
(g \in[0,1])[f(g, 1)=(1,0)], \& h<1 \rightarrow[f(1, h)=(0,1)] .
$$

Theorem 5 says that when insurance costs are lower for the consumers, a PLR is efficient with respect to the care levels as well as the insurance costs, if it sets the due care levels for both the parties and has the following structure: (i) whenever the firm is nonnegligent, the entire loss in the event of accident is borne by the consumer, irrespective of the level of care taken by the consumer, and (ii) when the firm is negligent and the consumer is not, the entire accident loss is borne by the firm. To see why, note that from Theorem 3, if a PLR sets the due care levels for both the parties then

$[(g \in[0,1])[f(g, 1)=(1,0)] \&(h \in[0,1))[f(1, h)=(0,1)]] \Rightarrow\left(x^{*}, y^{*}\right)$ is a unique N.E.

Since a firm can avoid liability simply by spending $y^{*}$ on care, it has strong incentive do so if it is risk-averse. Again, if we assume away the issue of moral hazards, the consumers will take efficient care even when they buy the insurance. In other words, if a PLR meets the requirements of Theorem 5, then it induces both the parties to opt for socially optimal care levels. That is, it is efficient with respect to the care levels even in the presence of risk-aversion. Moreover, under the rule at $\left(x^{*}, y^{*}\right)$, the consumer bears the entire expected loss. Therefore, the rule achieves efficiency on account of care levels as well as the insurance costs. The following corollary immediately follows from Theorem 5 .

Corollary 4 When the insurance costs are less for the firms, the rule of negligence with the defense of contributory negligence as well as the rule of comparative negligence are efficient in terms of care levels as well as the insurance costs.

\section{Product Liability Rules in India:}

The governing product liability law in India is the Consumer Protection Act, 1986. The Act holds a producer of a risky product liable if the product suffers from a defect 
or deficiency. The definition of 'defect' is provided in Sec 2(1f) of the Act. Under the Act, defect means any fault, imperfection or shortcoming in the quality, quantity, potency, purity or standard which is required to be maintained under the law in force. The ambit of the term 'law in force' is very broad. It includes not only the formal law but also the implied law in the form of industry standards and norms.

The notion of 'deficiency' is made precise in the Sec $2(1 \mathrm{~g})$ of the Act. It means any fault, imperfection, shortcoming or inadequacy in the quality, nature and manner of performance which is required to be maintained by the law in force. ${ }^{15}$

A remedy is available to the consumer when a court/consumer forum is convinced of there being a defect or deficiency in the product. The remedy includes an order to remove the defect, replace the good with compensation, return the price, or pay compensatory damages. In some rare instances courts have awarded punitive damages, especially when the defect is gross or when the seller/producer has resorted to unfair trade practices.

Therefore, Indian product liability law is like the simple rule of negligence. ${ }^{16}$ As our analysis shows, this rule is not efficient. At best this rule can induce firms to take efficient care when the care is unilateral, i.e., when only firms can take care. It cannot guarantee efficient consumption. Notice that this rule does not specify due care levels for both the parties. This means that when care is bilateral, Indian product liability law cannot ensure efficient care from both the parties. Moreover, the rule can be efficient with respect to the insurance costs only if consumers turn out to be the efficient risk bearers. However, in Indian scenario, where insurance market is at a nascent stage, it is the firms rather than consumers that are likely to be the efficient risk bearers.

There is yet another problem with Indian product liability law. A very few cases are actually litigated. Producers can escape liability in most of the instances of prod-

\footnotetext{
${ }^{15}$ The Act also has provisions against Unfair Trade practices. See Sec $2(1 \mathrm{r})$.

${ }^{16}$ In contrast, several versions of the rule of negligence, - e.g., rule of comparative negligence, rule of negligence with the defense of contributory negligence - are applied in case of motor vehicle accidents. See Singh (2004).
} 
uct caused injuries. ${ }^{17}$ Due to prolonged delays and legal uncertainty many people do not sue the producers. Therefore, the law does not provide enough deference to the producers.

\section{Remarks on the results and issues in further research}

We have analyzed the implications of different product liability rules when consumers do not have complete knowledge of product related risk. We have introduced a condition named the condition of negligent consumer's liability (NCL). When a product liability rule satisfies the condition NCL, a consumer can ensure full compensation in the event of accident merely by taking the due (efficient) care. As far as accident costs are concerned, the relevant result in the paper is Theorem 2. The theorem shows that when consumers do not know the risk correctly, a necessary and sufficient condition for the efficiency of a product liability rule is to satisfy the condition NCL.

Moreover, we have extended the economic analysis of product liability rules by incorporation insurance costs. We have studied the efficiency property of various product liability rules by making alternative assumptions about the insurance costs. Theorem 4 shows that if insurance costs are lower for firms then it is possible to have liability rules that are efficient with respect to the accident costs as well as the insurance costs. However, if insurance costs are lower for consumers, then there is a trade-off between the efficiency in terms of accident costs, on one hand, and that with respect to the insurance costs, on the other hand. However, Theorem 5 shows that even when consumers misperceive the product risk and have lower insurance costs, it possible to achieve the efficiency with respect to the insurance costs and still induce efficient care by both the parties. Therefore, the trade-off can be resolved to a significant extent. An implication of the results in the paper is that in an empirical or theoretical context if there are mechanisms that minimize inefficiency on account of the over or the under-consumption, then it is possible to achieve efficiency on all three fronts. Identification of such mechanisms and contexts requires further research. But, it is important to know that suitably constructed liability rules can, as we have shown, supplement other signaling mechanisms by providing information that is crucial for

\footnotetext{
${ }^{17}$ Some estimates suggest that all liability related disputes constitute only 3-5 per cent of cases lying pending before Indian courts. Moreover, most of liability suits concern motor vehicle accidents (Singh, 2004).
} 
economic efficiency.

Finally, our extension of economic analysis to cover insurance costs should be treated only as a one step in that direction. A more detailed analysis should consider the issues of moral hazards that are created by the introduction of insurance.

\section{APPENDIX}

We prove Theorem 1 by way of establishing the following two Lemmas. Lemmas 1 and 2 show the implications violations of condition NCL.

Lemma 1 For a PLR, $f$, if $[f(1,1)=(0,1)] \&(\exists h \in[0,1))[f(1, h) \neq(0,1)]$, then there exist $X, Y, L,\left(x^{*}, y^{*}\right)$ and $L_{c}$, satisfying (A1)- (A3), such that $f$ is not DAC minimizing.

Proof: Given $f(1,1)=(0,1)$ and $(\exists h \in[0,1))[f(1, h) \neq(0,1)]$. Suppose, $f(1, h)=$ $\left.\left(s_{1}, t_{1}\right)\right]$, where $t_{1} \in[0,1)$. Let $k>0$. As $t_{1}<1, t_{1} k<k$. Choose $r>0$ such that $t_{1} k<r<k$. Now, consider the accident context characterized by the following specification of $X, Y, L$ and $L_{c}: X=\left\{0, x_{0}\right\}, x_{0}>0$,

$Y=\left\{0, h y_{0}, y_{0}\right\}$, where $y_{0}=r /(1-h)$,

$L(0,0)=\Delta+k+h y_{0}+x_{0}+\delta$, where $\Delta \geq 0$, and $\delta>0$,

$L\left(0, h y_{0}\right)=\Delta+k+x_{0}+\delta, \quad L\left(0, y_{0}\right)=\Delta+x_{0}+\delta$,

$L\left(x_{0}, 0\right)=\Delta+h y_{0}+k, \quad L\left(x_{0}, h y_{0}\right)=\Delta+k, \quad$ and $L\left(x_{0}, y_{0}\right)=\Delta$.

It is clear that $\left(x_{0}, y_{0}\right)$ is a unique DAC minimizing configuration. Let $\left(x^{*}, y^{*}\right)=$ $\left(x_{0}, y_{0}\right)$. Take any $L_{c}$. Given $x_{0}$ opted by the consumer, $f(1,1)=(0,1)$ implies that if the firm chooses $y_{0}$ its expected accident costs are $y_{0}+\Delta$. And, if it chooses $h y_{0}$, its expected costs are $h y_{0}+t_{1}(\Delta+k)$. But, $y_{0}-h y_{0}>t_{1} k$, i.e., $y_{0}>h y_{0}+t_{1} k$. Thus, $y_{0}+\Delta>h y_{0}+t_{1}(\Delta+k)$, since $t_{1}<1$. That is, given $x_{0}$ opted by the consumer, the firm is better-off choosing $h y_{0}$ rather than $y_{0}$ and, hence the uniquely DAC minimizing configuration, $\left(x^{*}, y^{*}\right)=\left(x_{0}, y_{0}\right)$ is not a N.E. Therefore, there exist $X, Y, L,\left(x^{*}, y^{*}\right)$, and $L_{c}$, satisfying (A1)- (A3), such that $f$ is not DAC minimizing.

Lemma 2 For a PLR, $f$, if $(\exists g \in[0,1))[f(g, 1) \neq(1,0)]$ holds, then there exist $X$, $Y, L,\left(x^{*}, y^{*}\right)$ and $L_{c}$, satisfying (A1)- (A3), such that $f$ is not DAC minimizing.

Proof: Given $(\exists g \in[0,1))[f(g, 1) \neq(1,0)]$. Let, $f(g, 1)=\left(s_{1}, t_{1}\right)$ where $s_{1}<1$. For any $k>0, s_{1} k<k$. Choose $r>0$ such that $s_{1} k<r<k$. Now, consider the following 
$X, Y$ and $L: \quad X=\left\{0, g x_{0}, x_{0}\right\}$, where $x_{0}=r /(1-g)$,

$Y=\left\{0, y_{0}\right\}, y_{0}>0$,

$L(0,0)=\Delta+g x_{0}+k+y_{0}+\delta$, where $\delta>0$, and $\Delta \geq 0$,

$L\left(g x_{0}, 0\right)=\Delta+k+y_{0}+\delta, \quad L\left(x_{0}, 0\right)=\Delta+y_{0}+\delta$,

$L\left(0, y_{0}\right)=\Delta+g x_{0}+k, \quad L\left(g x_{0}, y_{0}\right)=\Delta+k, \quad L\left(x_{0}, y_{0}\right)=\Delta$.

Again, $\left(x_{0}, y_{0}\right)$ is a unique DAC minimizing configuration. Let $\left(x^{*}, y^{*}\right)=\left(x_{0}, y_{0}\right)$. Now, let $y_{0}$ be opted by the firm. When $\Delta=0$, it is easy to see that for any $L_{c} \leq L$ the consumer will be better-off choosing $g x_{0}$ rather than $x_{0}$. Next, consider the case when $\Delta>0$. Let, $L_{c}=\beta L$, where $\beta>0$. If the consumer chooses $x_{0}$ his expected accident costs are at least $x_{0}$. And, if he chooses $g x_{0}$, his expected costs are $g x_{0}+s_{1} \beta(\Delta+k)$. Now, whenever $k /(\Delta+k) \geq \beta>\min \left\{x_{0} /\left(g x_{0}+k\right), y_{0} /\left(y_{0}+\delta\right)\right\}$ it is easy to see that $g x_{0}+s_{1} \beta(\Delta+k) \leq g x_{0}+s_{1} k$. As $g x_{0}+s_{1} k<x_{0}$ by construction, $g x_{0}+s_{1} \beta(\Delta+k)<x_{0}$. Thus, $\left(x^{*}, y^{*}\right)=\left(x_{0}, y_{0}\right)$ is not a N.E. Therefore, there exist $X, Y, L,\left(x^{*}, y^{*}\right)$, and $L_{c}$, satisfying (A1)- (A3) such that $f$ is not DAC minimizing.

Proof of Theorem 1: Suppose not. Suppose there exists a PLR, $f$, such that $f$ violates NCL and is efficient for every $X, Y, L,\left(x^{*}, y^{*}\right), L_{c}$, satisfying (A1)- (A3), and every $C(q) . f$ violates NCL $\rightarrow(i)(\exists h \in[0,1])[f(1, h) \neq(0,1)]$, or $(i i)(\exists g \in[0,1))$ $[f(g, 1) \neq(1,0)]$.

Case 1: Suppose, $(i)$, i.e., $(\exists h \in[0,1])[f(1, h) \neq(0,1)]$ holds. There are only two mutually exclusive possibilities: $f(1,1)=(0,1)$ or $f(1,1) \neq(0,1)$.

Subcase 1: $f(1,1)=(0,1)$ : When $f(1,1)=(0,1)$ is true, $(\exists h \in[0,1])[f(1, h) \neq$ $(0,1)] \rightarrow(\exists h \in[0,1))[f(1, h) \neq(0,1)]$. But, when $f(1,1)=(0,1) \&(\exists h \in$ $[0,1))[f(1, h) \neq(0,1)]$, from Lemma $1, f$ cannot be DAC minimizing for all $X$, $Y, L,\left(x^{*}, y^{*}\right)$, and $L_{c}$. As a consequence, $f$ cannot be efficient for every $X, Y, L$, $\left(x^{*}, y^{*}\right), L_{c}$, and $C(q)$.

Subcase 2: $f(1,1) \neq(0,1)$ : Let $f(1,1)=\left(s_{1}, t_{1}\right)$, where $s_{1}>0$. Consider any $X$, $Y, L,\left(x^{*}, y^{*}\right)$, and $L_{c}$, such that $\left(x^{*}, y^{*}\right)$ is uniquely DAC minimizing. In such contexts whenever there is no N.E., or when $\left(x^{*}, y^{*}\right)$ is not a unique N.E., $f$ is not DAC minimizing and therefore not efficient. When $\left(x^{*}, y^{*}\right)$ is a unique N.E., though DAC minimizing, $f$ is not efficient. As, in equilibrium $s=s_{1}>0,(9) \&(10)$ will be different from (2)\&(3). So, the outcome will not be efficient in terms of total quantity produced (Remark 2).

Case 2: Let $(i i)$, i.e., $(\exists g \in[0,1))[f(g, 1) \neq(1,0)]$ hold. In this case also from Lemma 
2, for some $X, Y, L,\left(x^{*}, y^{*}\right)$, and $L_{c}, f$ is not DAC minimizing.

Therefore, it cannot be the case that $f$ violates condition NCL and is still efficient for every possible $X, Y, L,\left(x^{*}, y^{*}\right), L_{c}$, and every $C(q)$.

Lemma 3 If a PLR satisfies the condition NCL then for every possible choice of $X$, $Y, L,\left(x^{*}, y^{*}\right)$, and $L_{c}$ satisfying $(\mathrm{P} 1),\left(x^{*}, y^{*}\right)$ is a N.E.

Proof: Let the PLR, $f$, satisfy the condition NCL. Take any arbitrary $X, Y, L$, $\left(x^{*}, y^{*}\right)$ and any $L_{c}$ satisfying $(\mathrm{P} 1)$. As $f$ satisfies the condition NCL, $f(1,1)=(0,1)$. Let $y=y^{*}$ be opted by the firm. Then, for all $x \geq x^{*}$, the expected accident costs of the consumer are $x+s\left[g(x), h\left(y^{*}\right)\right] L_{c}\left(x, y^{*}\right)=x$, as when $x \geq x^{*}, s\left[g(x), h\left(y^{*}\right)\right]=0$ by condition NCL. So, if the consumer chooses $x^{*}$ his expected accident costs are only $x^{*}$. Now, consider a choice of $x^{\prime} \neq x^{*}$ by the consumer. First, consider the case when $x^{\prime}>x^{*}$. In this case his expected accident costs clearly are $x^{\prime}$, and he will be strictly worse-off choosing $x^{\prime}$ rather than $x^{*}$. Now, consider the case $x^{\prime}<x^{*}$. For $x^{\prime}<$ $x^{*}$, the expected accident costs of the consumer are $x^{\prime}+s\left[g\left(x^{\prime}\right),\left(y^{*}\right)\right] L_{c}\left(x^{\prime}, y^{*}\right)$, i.e., $x^{\prime}+L_{c}\left(x^{\prime}, y^{*}\right)$, as when $x^{\prime}<x^{*}, s\left[g\left(x^{\prime}\right),\left(y^{*}\right)\right]=1$ by condition NCL. But, the choice of $x^{\prime}$ can be better than that of $x^{*}$ for the consumer only if $x^{\prime}+L_{c}\left(x^{\prime}, y^{*}\right)<x^{*}$, i.e., only if $x^{\prime}+y^{*}+L_{c}\left(x^{\prime}, y^{*}\right)<x^{*}+y^{*}$. This implies $x^{\prime}+y^{*}+L_{c}\left(x^{\prime}, y^{*}\right)<x^{*}+y^{*}+L_{c}\left(x^{*}, y^{*}\right)$. But, in view of $(\mathrm{P} 1)$ this is a contradiction.

Thus, given that $y^{*}$ is opted by the firm, $x^{*}$ is a best response by the consumer.

Next, let $x^{*}$ be opted by the consumer. This, in view of condition NCL implies that the expected costs of the firm are $y+L\left(x^{*}, y\right)$. By assumption, $x^{*}+y+L\left(x^{*}, y\right)$ and therefore $y+L\left(x^{*}, y\right)$ is uniquely minimized at $y^{*}$. That is, given that $x^{*}$ is opted by the consumer, $y^{*}$ is a best response by the firm.

Hence $\left(x^{*}, y^{*}\right)$ is a N.E.

Lemma 4 If a PLR satisfies condition NCL then for every possible choice of $X, Y$, $L,\left(x^{*}, y^{*}\right)$, and $L_{c}$ satisfying $(\mathrm{P} 1)$,

$$
(\forall(\bar{x}, \bar{y}) \in X \times Y)\left[(\bar{x}, \bar{y}) \text { is a N.E. } \rightarrow(\bar{x}, \bar{y})=\left(x^{*}, y^{*}\right)\right]
$$

Proof: Let PLR $f$ satisfy condition NCL. Take any arbitrary $X, Y, L,\left(x^{*}, y^{*}\right)$, and any $L_{c}$ satisfying $(\mathrm{P} 1)$. Suppose $(\bar{x}, \bar{y}) \in X \times Y$ is a N.E. $(\bar{x}, \bar{y})$ is a N.E. implies that if $\bar{y}$ is opted by the firm, expected accident costs of the consumer are minimum at $\bar{x}$, 
i.e.,

$$
(\forall x \in X)\left[\bar{x}+s[g(\bar{x}), h(\bar{y})] L_{c}(\bar{x}, \bar{y}) \leq x+s[g(x), h(\bar{y})] L_{c}(x, \bar{y})\right]
$$

and if $\bar{x}$ is opted by the consumer, expected accident costs of the firm are minimum at $\bar{y}$, i.e.,

$$
(\forall y \in Y)[\bar{y}+t[g(\bar{x}), h(\bar{y})] L(\bar{x}, \bar{y}) \leq y+t[g(\bar{x}), h(y)] L(\bar{x}, y)]
$$

Now, (12), in particular, $\rightarrow \bar{x}+s[g(\bar{x}), h(\bar{y})] L_{c}(\bar{x}, \bar{y}) \leq x^{*}+s\left[g\left(x^{*}\right), h(\bar{y})\right] L_{c}\left(x^{*}, \bar{y}\right)$, i.e.,

$$
\bar{x}+s[g(\bar{x}), h(\bar{y})] L_{c}(\bar{x}, \bar{y}) \leq x^{*}
$$

as $s\left[g\left(x^{*}\right), h(\bar{y})\right]=0$ by condition NCL. And, $(13) \rightarrow$

$$
\bar{y}+t[g(\bar{x}), h(\bar{y})] L(\bar{x}, \bar{y}) \leq y^{*}+t\left[g(\bar{x}), h\left(y^{*}\right)\right] L\left(\bar{x}, y^{*}\right)
$$

Adding (14) and (15)

$$
\bar{x}+\bar{y}+s[g(\bar{x}), h(\bar{y})] L_{c}(\bar{x}, \bar{y})+t[g(\bar{x}), h(\bar{y})] L(\bar{x}, \bar{y}) \leq x^{*}+y^{*}+t\left[g(\bar{x}), h\left(y^{*}\right)\right] L\left(\bar{x}, y^{*}\right)
$$

Case 1: $\bar{x} \geq x^{*}$ :

$(\forall h \in[0,1])[f(1, h)=(0,1)]$ by condition NCL. Thus, when $\bar{x} \geq x^{*}, s[g(\bar{x}), h(\bar{y})]=0$, $t[g(\bar{x}), h(\bar{y})]=1$, and $t\left[g(\bar{x}), h\left(y^{*}\right)\right]=1$. Therefore, from $(16),(\bar{x}, \bar{y})$ is a N.E. $\rightarrow$ $\bar{x}+\bar{y}+L(\bar{x}, \bar{y}) \leq x^{*}+y^{*}+L\left(\bar{x}, y^{*}\right)$. Now, $\bar{x} \geq x^{*} \rightarrow L\left(\bar{x}, y^{*}\right) \leq L\left(x^{*}, y^{*}\right)$. Therefore, we get $\bar{x}+\bar{y}+L(\bar{x}, \bar{y}) \leq x^{*}+y^{*}+L\left(x^{*}, y^{*}\right)$. But, $\bar{x}+\bar{y}+L(\bar{x}, \bar{y}) \geq x^{*}+y^{*}+L\left(x^{*}, y^{*}\right)$, as $\left(x^{*}, y^{*}\right)$ is DAC minimizing. This implies that $(\bar{x}, \bar{y})$ can be a N.E. only if $(\bar{x}, \bar{y})=$ $\left(x^{*}, y^{*}\right)$. Thus,

$$
\bar{x} \geq x^{*} \&(\bar{x}, \bar{y}) \text { is a } N . E . \rightarrow(\bar{x}, \bar{y})=\left(x^{*}, y^{*}\right)
$$

Case 2: $\bar{x}<x^{*}$ :

Subcase 1: $\bar{y} \geq y^{*}:$ As $(\forall g \in[0,1))[f(g, 1)=(1,0)$ by condition NCL, in this case $s[g(\bar{x}), h(\bar{y})]=1, t[g(\bar{x}), h(\bar{y})]=0$ and $t\left[g(\bar{x}), h\left(y^{*}\right)\right]=0$. So, (16), reduces to $\bar{x}+\bar{y}+L_{c}(\bar{x}, \bar{y}) \leq x^{*}+y^{*}$. Thus, $\bar{x}+\bar{y}+L_{c}(\bar{x}, \bar{y}) \leq x^{*}+y^{*}+L_{c}\left(x^{*}, y^{*}\right)$, which is a contradiction in view of (P1). Therefore,

$$
\text { if } \bar{x}<x^{*} \& \bar{y} \geq y^{*} \text {, then }(\bar{x}, \bar{y}) \text { cannot be a N.E. }
$$

Subcase 2: $\bar{y}<y^{*}$ : Suppose $f(g(\bar{x}), h(\bar{y}))=(\bar{s}, \bar{t})$. Let

$$
t^{*}=\frac{y^{*}-\bar{y}}{\left(x^{*}-\bar{x}\right)+\left(y^{*}-\bar{y}\right)} \text { and } s^{*}=\frac{x^{*}-\bar{x}}{\left(x^{*}-\bar{x}\right)+\left(y^{*}-\bar{y}\right)} \text {. }
$$


There are two possible cases: $(i) \bar{t} \geq t^{*}$, or $(i i) \bar{t}<t^{*}$. When $(i)$ holds, from (15), $(\bar{x}, \bar{y})$ is a N.E. $\rightarrow \bar{y}+\bar{t} L(\bar{x}, \bar{y}) \leq y^{*}$, since when $\bar{x}<x^{*}, t\left[g(\bar{x}), h\left(y^{*}\right)\right]=0$ by NCL. That is, we get $\bar{t} L(\bar{x}, \bar{y}) \leq y^{*}-\bar{y}$, i.e.,

$$
\frac{y^{*}-\bar{y}}{\left(x^{*}-\bar{x}\right)+\left(y^{*}-\bar{y}\right)} L(\bar{x}, \bar{y}) \leq y^{*}-\bar{y}, \quad \text { as } \quad \bar{t} \geq t^{*} \rightarrow t^{*} L(\bar{x}, \bar{y}) \leq \bar{t} L(\bar{x}, \bar{y}) .
$$

So, when $(i)$ holds $(\bar{x}, \bar{y})$ is a N.E. $\rightarrow \bar{x}+\bar{y}+L(\bar{x}, \bar{y}) \leq x^{*}+y^{*}$, i.e., $\bar{x}+\bar{y}+L(\bar{x}, \bar{y}) \leq x^{*}+y^{*}+L\left(x^{*}, y^{*}\right)$, which is a contradiction because $\left(x^{*}, y^{*}\right)$.

When (ii) holds, i.e., when $\bar{t}<t^{*}, \bar{s}+\bar{t}=1=s^{*}+t^{*}$ implies $\bar{s}>s^{*}$. When $\bar{s}>s^{*}$, from $(14)(\bar{x}, \bar{y})$ is a N.E. $\rightarrow \bar{s} L_{c}(\bar{x}, \bar{y}) \leq x^{*}-\bar{x} . \quad s^{*}<\bar{s} \rightarrow s^{*} L_{c}(\bar{x}, \bar{y}) \leq \bar{s} L_{c}(\bar{x}, \bar{y})$. Thus, in this subcase $(\bar{x}, \bar{y})$ is a N.E. implies $s^{*} L_{c}(\bar{x}, \bar{y}) \leq x^{*}-\bar{x}$, i.e.,

$$
\frac{x^{*}-\bar{x}}{\left(x^{*}-\bar{x}\right)+\left(y^{*}-\bar{y}\right)} L_{c}(\bar{x}, \bar{y}) \leq x^{*}-\bar{x}, \quad \text { i.e., } \quad \bar{x}+\bar{y}+L_{c}(\bar{x}, \bar{y}) \leq x^{*}+y^{*}
$$

a contradiction in view of (P1). Therefore,

$$
\text { if } \bar{x}<x^{*} \& \bar{y}<y^{*} \text {, then }(\bar{x}, \bar{y}) \text { cannot be a N.E. }
$$

Finally, $(17)-(19) \rightarrow\left[(\bar{x}, \bar{y})\right.$ is a N.E. $\left.\rightarrow(\bar{x}, \bar{y})=\left(x^{*}, y^{*}\right)\right]$

Proof of Theorem 2: Suppose a PLR, denoted by $f$, satisfies the condition NCL. Given that $f$ satisfies the condition NCL, there are two mutually exclusive possibilities: (i) $f$ specifies the due care levels for both the parties, (ii) $f$ specifies the due care level for only the consumer.

Case 1: Suppose (i) holds. In this case, as is argued before, the expected loss function $L_{c}$ will satisfy $(\mathrm{P} 1)$. Now Lemmas 3 and 4 imply that for every $X, Y, L,\left(x^{*}, y^{*}\right)$, and $L_{c},\left(x^{*}, y^{*}\right)$ is a unique N.E., i.e., $f$ is DAC minimizing.

Case 2: Suppose (ii) holds. In this case as the care level of the firm is irrelevant from legal point of view, the liability assignment cannot be conditioned on its care level; it will have to be conditioned only on the care level of the consumer. Therefore, in this case the condition NCL would imply that the rule, $f$, be such that $(\forall h \in[0,1])[g<1 \rightarrow f(g, h)=(1,0) \& g=1 \rightarrow f(g, h)=(0,1)]$. Under such a liability assignment, $\left(x^{*}, y^{*}\right)$ is a unique N.E. To see why, note that the consumer will never opt for $x>x^{*}$, i.e., he will always choose a $x$ such that $x \leq x^{*}$. If the consumer opts for $x^{*}$ his expected accident costs are simply $x^{*}$; on the other hand, if he opts for some $x<x^{*}$ his expected accident costs will be $x+L_{c}(x, y)$, where $y$ is the care level opted by the firm. Remember that from the liability rule 
itself, the consumer knows that $x^{*}$ along with some $y$ minimizes DAC. Let $y^{\prime}$ solve $\min _{y}\left\{x^{*}+y+L_{c}\left(x^{*}, y\right)\right\}$, i.e., according to the consumer $\left(x^{*}, y^{\prime}\right)$ minimizes DAC. Therefore, $\left(\forall x<x^{*}\right)\left[x+y^{\prime}+L_{c}\left(x, y^{\prime}\right)>x^{*}+y^{\prime}\right]$, i.e., $x+L_{c}\left(x, y^{\prime}\right)>x^{*}$. It is immediate to see that for any $x<x^{*}$ opted by the victim, $y=0$ is a uniquely best response for the firm. Therefore, from the perspective of a rational consumer, under the PLR, $y$ opted by the firm is such that $y \leq y^{\prime}$. But, $\left(\forall y \leq y^{\prime}\right)\left[x+L_{c}(x, y) \geq x+L_{c}\left(x, y^{\prime}\right)\right]$, i.e., $x+L_{c}(x, y)>x^{*}$. Thus, under $f$, opting for $x^{*}$ is a strictly dominant strategy for the consumer. It is easy to see that given $x^{*}$ opted by the consumer, $y^{*}$ is a uniquely best response for the firm. Again, $\left(x^{*}, y^{*}\right)$ is a unique N.E.

Therefore, if a PLR, $f$, satisfies the condition NCL, then for every $X, Y, L$, $\left(x^{*}, y^{*}\right)$, and $L_{c},\left(x^{*}, y^{*}\right)$ is a unique N.E.

Now, $\left(x^{*}, y^{*}\right)$ is a unique N.E. and condition NCL imply that in equilibrium $s=0$ and $t=0$. As a consequence, (10)\&(11) will be identical with (2)\&(3). This implies that $q^{*}$ and $n^{*}$ will solve (10)\&(11), simultaneously (Remark 2). Therefore, $f$ is efficient for every $X, Y, L,\left(x^{*}, y^{*}\right)$, and $L_{c}$.

Proof of Theorem 3: Note that under a PLR, as in the statement of Theorem 3, $L_{c}$ satisfies the Property $(\mathrm{P} 1)$. When $f(1,1)=(0,1)$ hold, i.e., when the firm is the residual loss bearer of accident loss, the rule satisfies the condition NCL and therefore, by Lemmas 2 and 3, is DAC minimizing.

Therefore, consider the case when $f(1,1)=(1,0)$, i.e., when the consumer is the residual loss bearer. Let $x=x^{*}$ be opted by the consumer. Then, $f(1,1)=(1,0)$, implies that for all $y \geq y^{*}$, the expected accident costs of the firm are simply $y$. So, the firm will not opt for any $y^{\prime}>y^{*}$. Now, consider a choice of $y^{\prime}<y^{*}$ by the firm. For $y^{\prime}<y^{*}$, the expected accident costs of the firm are $y^{\prime}+L\left(x^{*}, y^{\prime}\right)$. But, the choice of $y^{\prime}$ can be better than that of $y^{*}$ for the firm only if $y^{\prime}+L\left(x^{*}, y^{\prime}\right)<y^{*}$, i.e., only if $x^{*}+y^{\prime}+L\left(x^{*}, y^{\prime}\right)<x^{*}+y^{*}$. This implies $x^{*}+y^{\prime}+L\left(x^{*}, y^{*}\right)<x^{*}+y^{*}+L\left(x^{*}, y^{*}\right)$. But, in view of (A5) this is a contradiction. Thus, given that $x^{*}$ is opted by the consumer, $y^{*}$ is a best response by the firm.

Next, let $y^{*}$ be opted by the firm. This, in view of $p<1 \Rightarrow f(p, 1)=(1,0)$ and $f(1,1)=(1,0)$, implies that the expected costs of the consumer are $x+L_{c}\left(x, y^{*}\right)$. By Property $(\mathrm{P} 1), x+y^{*}+L_{c}\left(x, y^{*}\right)$ and therefore $x+L_{c}\left(x, y^{*}\right)$ is uniquely minimized at $x^{*}$. That is, given that $y^{*}$ is opted by the firm, $x^{*}$ is a best response by the consumer.

Hence $\left(x^{*}, y^{*}\right)$ is a N.E. Furthermore, arguing along the lines in the proof for 
Lemma 4 , it can be shown that $\left(x^{*}, y^{*}\right)$ is a unique N.E.

\section{References}

American Law Institute (1997), Restatement of the Law (Third) of Torts: Products Liability, Philadelphia, The American Law Institute.

Arlen, J (2000), 'Damages' in Encyclopedia of Law and Economics, Bouckaert, Boudewijn and De Geest, Gerrit (eds.), Cheltenham, Edward Elgar.

Bagwell, Kyle and Riordan, Michael H. (1991), 'High and Declining Prices Signal Product Quality', 81 American Economic Review, 224-239.

Beales, J. Howard, III, Craswell, Richard and Salop, Steven C. (1981), 'The Efficient Regulation of Consumer Information', 24 Journal of Law and Economics, 491-539. Boyd, (1994), Risk, Liability and Monopoly, International Journal of the Economics of Business, Vol. 1, 387-403.

Burrows, Paul (1992), 'Consumer Safety under Products Liability and Duty to Disclose', 12 International Review of Law and Economics, 457-478.

Caves, R.E. and Greene, D.P. (1996), 'Brands' Quality Levels, Prices, and Advertising Outlays: Empirical Evidence on Signals and Information Costs', 14 International Journal of Industrial Organization, 29-52.

Doughety, Andrew, F and Reinganum, Jennifer, F. (1997), 'Everybody Out of Pool: Producer Liability, Punitive Damages, and Competition', 13 Journal of Law, Economics and Organization, 410-432.

Epple, Dennis and Raviv, Artur (1978), 'Product Safety: Liability Rules, Market Structure, and Imperfect Information', 68 American Economic Review, 80-95.

Emons, W. (1990), 'Efficient liability rules for an economy with non-identical individuals', Journal of Public Economics, 42, 89-104.

Emons, W. and Sobel, J. (1991), 'On the effectiveness of liability rules when agents are not identical', Review of Economic Studies, 58 , 375-390.

Endres Alfred and Lüdeke Andreas, (1998) ‘ Limited Liability and Imperfect InformationOn existence of safety equlibria under product liability,' 5, European Journal of Law and Economics, 153-65.

Epstein, Richard A. (1985), 'Products Liability as an Insurance Market', 14 Journal of Legal Studies, 645-669.

Geistfeld, Mark (1992), 'Implementing Enterprise Liability: A Comment on Henderson and Twerski', 67 New York University Law Review, 1157 ff. 
Geistfeld, Mark (1995), 'Manufacturer Moral Hazard and the Tort Contract Issue in Products Liability', 15 International Review of Law and Economics, 241-257.

Geistfeld, Mark (2000), 'Product Liability' in Encyclopedia of Law and Economics, Bouckaert, Boudewijn and De Geest, Gerrit (eds.), Cheltenham, Edward Elgar.

Goldberg, Victor P. (1974), 'The Economics of Product Safety and Imperfect Information', 5 Bell Journal of Economics and Management Science, 683-688.

Grossman, Sanford J. (1981), 'The Informational Role of Warranties and Private Disclosure about Product Quality', 24 Journal of Law and Economics, 461-483.

Hamada, Koichi (1976), 'Liability Rules and Income Distribution in Products Liability', 66 American Economic Review, 228-234.

Hamilton, Stephen F., (1998), 'Taxation, Fines, and Producer Liability Rules: Efficiency and Market Structure Implications', 65, Southern Economic Journal, 140-150. Harvey, Brian, H. and Parry Deborah, L. (2000), The Law of Consumer Protection and Fair Trading, 6th Edi., Butterworth, London.

Jain, S.K and Singh, R. (2002), "Efficient Liability Rules: Complete Characterization", 75, Journal of Economics, 105-124.

Jones, P. and Hudson, J. (1996), 'Signalling Product Quality: When is Price Relevant?', 30 Journal of Economic Behavior and Organization, 257-66.

Kambhu, John (1982), 'Optimal Product Quality under Asymmetric Information and Moral Hazard', Bell Journal of Economics, 483-492.

Landes, W. M. and Posner, R. A. (1987), The Economic Structure of Tort Law, Cambridge (MA), Harvard University Press.

Marino, Anthony M. (1988), 'Products Liability and Scale Effects in a Long-Run Competitive Equilibrium', 8 International Review of Law and Economics, 97-107.

McKean, Roland N. (1970), 'Products Liability: Implications of Some Changing Property Rights', 84 Quarterly Journal of Economics, 611-626.

Miceli, T. J. (1997), Economics of the Law: Torts, Contracts, Property, Litigation, Oxford, Oxford University Press.

Oi, Walter Y. (1973), 'The Economics of Product Safety', 4 Bell Journal of Economics, 3-28.

Polinsky, A. M (1980), 'Strict Liability versus Negligence in a Market Setting', 70 American Economic Review , 363-367.

Priest, George L. (1981), 'A Theory of the Consumer Product Warranty', 90 Yale Law Journal, 1297-1352. 
Priest, George L. (1987), 'The Current Insurance Crisis and Modern Tort Law', 96 Yale Law Journal, 1521-1590.

Priest, George L. (1991), 'The Modern Expansion of Tort Liability: Its Sources, Its Effects, and Its Reform', 5(3) Journal of Economic Perspectives, 31-50.

Schlee, Edward E. (1996), 'The Value of Information about Product Quality', 27RAND Journal of Economics, 803-815.

Schwartz, Alan (1995), 'Legal Implications of Imperfect Information in Consumer Markets', 151 Journal of Institutional and Theoretical Economics, 31-48.

Schwartz, Alan and Wilde, Louis L. (1985), 'Product Quality and Imperfect Information', 52 Review of Economic Studies, 251-262.

Shavell, S. (1980), 'Strict liability versus negligence' Journal of Legal Studies, 9, 1-25.

Shavell, S. (1987), Economic Analysis of Accident Law, Cambridge (MA), Harvard.

Simon, Marilyn J. (1981), 'Imperfect Information, Costly Litigation, and Product Quality', 12 Bell Journal of Economics, 171-184.

Singh, R. (2004), 'Economics of Judicial Decision Making in Indian Tort Law: Motor Accident Cases', 39(25), Economic and Political Weekly, 2603-2616.

Singh, R. (2003), 'Efficiency of 'simple' liability rules when courts make erroneous estimation of the damage', 16, European Journal of Law and Economics, 39-58.

Spence, A. Michael (1977), 'Consumer Misperception, Product Failure and Product Liability', 44 Review of Economic Studies, 561-572.

Sunding, David L and Zilberman, David, (1998), 'Allocating Products Liability in Multimarket Setting', 18 International Review of Law and Economics,, 1-11.

Viscusi, W. Kip (1991), Reforming Products Liability, Cambridge, MA, Harvard University Press.

Viscusi, W. Kip, (2006) "Liability", The Concise Encyclopedia of Economics. Liberty

Fund, Inc. Ed. David R. Henderson. Library of Economics and Liberty.jhttp://www.econlib.org/lib Legal Acts:

The Consumer Protection Act, 1986 